\title{
AVALIAÇÃO DO POTENCIAL FISIOLÓGICO DE LOTES DE SEMENTES DE SOJA ${ }^{1}$
}

\author{
JULIANA FARIA DOS SANTOS², RENATA OLIVEIRA ALVARENGA ${ }^{3}$, \\ TATHIANA SILVA TIMÓTEO ${ }^{3}$, ELENICE DE CÁSSIA CONFORTO ${ }^{4}$, \\ JULIO MARCOS FILHO ${ }^{5}$, ROBERVAL DAITON VIEIRA ${ }^{6}$
}

\begin{abstract}
RESUMO - Vários procedimentos são utilizados para avaliar o potencial fisiológico de sementes, sendo fundamental a utilização daqueles que reflitam melhor o desempenho em campo. A pesquisa teve como objetivo avaliar o potencial fisiológico de sementes de soja por meio de testes de avaliação rápida, de vigor, de emergência de plântulas em campo e análise computadorizada de imagens $\left(\mathrm{SVIS}^{\circledR}\right)$, procurando identificar o procedimento mais eficiente na separação de lotes. Cinco lotes das cultivares BRS Valiosa RR e CD 208 foram avaliados em duas épocas (antes e após armazenamento) pelos testes de germinação, de avaliação rápida (embebição em água e pH do exsudato), de vigor (envelhecimento acelerado e condutividade elétrica), de emergência de plântulas em campo e análise computadorizada de imagens $\left(\right.$ SVIS $\left.^{\circledR}\right)$. Os testes de germinação em areia, de condutividade elétrica e de embebição em água foram eficientes na separação dos lotes, mas apenas este último possibilitou identificar diferenças consistentes entre os lotes nos dois períodos avaliados. Assim, o teste de embebição em água pode ser considerado promissor na composição de programas de controle de qualidade.
\end{abstract}

Termos para indexação: Glycine max, embebição em água, pH do exsudato, vigor, SVIS ${ }^{\circledR}$.

\section{PHYSIOLOGICAL POTENTIAL OF SOYBEAN SEED LOTS}

\begin{abstract}
Several procedures can be used to evaluate the physiological potential of soybean seeds, but it is fundamental that reliable procedures are associated with the field performance of the seed lots. This research aimed to evaluate the physiological potential of soybean seed lots with quick tests, as well as vigor assessment, seedling field emergence and the computer image analysis system $\left(\mathrm{SVIS}^{\mathbb{R}}\right)$, to identify the most efficient procedure for classifying soybean seed lots. The physiological potential of five seed lots of 'BRS Valiosa RR' and 'CD 208' was evaluated for two periods (before and after cold room storage) by the germination test (paper and sand), rapid evaluation tests (water imbibition and $\mathrm{pH}$ exudates), vigor tests (accelerated aging and electrical conductivity), seedling field emergence and the computer image analysis system (SVIS ${ }^{\circledR}$ ). Germination (sand substrate), electrical conductivity and water imbibition tests were effective in separating the seed lots of both cultivars, but only the water imbibition test allowed classification in both evaluation periods. The water imbibition test is therefore considered as promising for evaluating physiological potential during seed production and storage.
\end{abstract}

Index terms: Glycine max, water imbibition, $\mathrm{pH}$ exudates, vigor, SVIS ${ }^{\circledR}$.

${ }^{1}$ Submetido em 21/03/2011. Aceito para publicação em 01/04/2011. Trabalho de conclusão de curso do primeiro autor apresentado à UNESP/ São José do Rio Preto. Processo FAPESP no 2009/00963-8

${ }^{2}$ Mestranda em Agronomia (Produção Vegetal), UNESP, 14884-900 Jaboticabal, SP julianafariaa@hotmail.com

${ }^{3}$ Doutoranda em Fitotecnia, Depto. Produção Vegetal, USP/ESALQ, Caixa Postal 9, 13418-900 Piracicaba, SP realvarenga7@gmail.com, tasiti@yahoo.com.br

${ }^{4}$ Professora Assistente Doutor, Depto. Zoologia e Botânica, UNESP, 15054-000 São José do Rio Preto, SP elenice@ibilce.unesp.br

${ }^{5}$ Professor Titular, Depto. Produção Vegetal, USP/ESALQ, Piraciaba, SP, jmarcos@esalq.usp.br (Bolsista do CNPq)

${ }^{6}$ Professor Titular, Depto. Produção Vegetal, UNESP, Jaboticabal, SP , rdvieira@fcav.unesp.br (Bolsista do CNPq). 


\section{INTRODUÇÃO}

Durante as últimas décadas, o interesse em desenvolver técnicas apropriadas para obter melhores informações sobre as culturas tem sido tópico central de pesquisas (Dell'aquila, 2009). No âmbito nacional, a avaliação dos efeitos do potencial fisiológico das sementes de soja sobre o estabelecimento e desempenho de plântulas em condições de campo é extremamente relevante, devido à importância dessa cultura no contexto do agronegócio e da economia brasileira (Schuch et al., 2009).

A utilização de sementes de soja com alto potencial fisiológico é aspecto importante a ser considerado para o aumento da produtividade dessa cultura e, por isso, o controle de qualidade de sementes deve ser cada vez mais eficiente, incluindo testes que avaliem rapidamente o potencial fisiológico e que permitam diferenciação precisa entre lotes (Fessel et al., 2010).

Os testes de vigor têm constituído ferramentas de uso cada vez mais rotineiro pela indústria de sementes para a determinação do potencial fisiológico e, dentre os testes mais utilizados, estão o teste de envelhecimento acelerado e o teste de condutividade elétrica. Pesquisas realizadas envolvendo esses testes (Barros e Marcos Filho, 1997; Silva et al., 2008; Carvalho et al., 2009) mostraram que ambos são satisfatórios na avaliação do potencial fisiológico de sementes de soja.

Uma alternativa aos testes de vigor estão o teste de embebição em água e de $\mathrm{pH}$ do exsudato. Esses procedimentos apresentam em comum a redução do tempo mínimo necessário para obtenção dos resultados, normalmente menor que o estipulado nos procedimentos dos testes de vigor; envolvem a verificação do nível de desestruturação das membranas celulares e da integridade do tegumento. Esses testes evitam o descarte de sementes que aparentemente não se enquadram nos padrões mínimos de germinação e impedem o armazenamento desnecessário de lotes com baixo vigor (Amaral e Peske, 2000).

Barros e Marcos Filho (1990) verificaram que o teste de $\mathrm{pH}$ do exsudato é eficaz na separação de lotes e que a determinação da viabilidade, além de rápida, apresenta alta confiabilidade. O mesmo foi observado por Cabrera e Peske (2002) e Santana et al. (1998) em sementes de milho e por Amaral e Peske (2000) em sementes de trigo.

A hidratação e desidratação em campo devido ao retardamento da colheita da soja reduzem o potencial fisiológico, germinação e vigor de lotes de sementes, o que pode ser identificado pelo teste de embebição em água de sementes (Vieira et al., 1982). Entretanto, esse teste não permite a separação de genótipos quanto ao potencial fisiológico das sementes (Vieira et al., 1983; Rocha et al., 1984).

Embora vários procedimentos para realização dos testes de vigor e de avaliação rápida estejam estabelecidos, uma opção inovadora com relação à avaliação do potencial fisiológico é o uso da análise computadorizada de imagens de plântulas (Seed Vigor Imaging System - SVIS ${ }^{\circledR}$ ), desenvolvido por Sako et al. (2001) para determinação do vigor de sementes de alface. Essa técnica é relativamente simples e avalia rapidamente várias plântulas, representando economia significativa de tempo, em comparação à maioria dos testes para avaliação do vigor de sementes (Marcos Filho et al., 2009).

Assim, esta pesquisa teve como objetivo avaliar o potencial fisiológico de sementes de soja utilizando testes de avaliação rápida (teste de embebição em água e de $\mathrm{pH}$ do exsudato), testes de vigor (envelhecimento acelerado e condutividade elétrica), de emergência de plântulas em campo e análise computadorizada de imagens $\left(\mathrm{SVIS}^{\circledR}\right)$, procurando identificar o procedimento mais eficiente na separação de lotes de sementes de soja.

\section{MATERIAL E MÉTODOS}

O trabalho foi desenvolvido no Laboratório de Análise de Sementes do Departamento de Produção Vegetal, UNESP, Câmpus de Jaboticabal, utilizando sementes de soja provenientes de cinco lotes de cada um das cultivares, BRS Valiosa RR e CD 208, obtidos junto à Cooperativa das Agricultores da Região de Orlândia SP Ltda (CAROL). O potencial fisiológico das sementes foi avaliado por testes laboratoriais, em duas épocas diferentes (antes e após três meses de armazenamento em câmara fria, a $10{ }^{\circ} \mathrm{C}$ e $50 \%$ UR). No caso da análise computadorizada de imagens de plântulas, os procedimentos foram realizados junto ao Laboratório de Análise de Imagens do Departamento de Produção Vegetal da USP/ESALQ, Piracicaba, SP.

Para os testes realizados após o armazenamento, as sementes dos lotes 3, 4 e 5 de cada cultivar passaram por choque térmico em tempos diferentes, na tentativa de provocar diferenças entre os lotes, cujos experimentos iniciais demonstraram potencial fisiológico muito semelhante. Os lotes 3 e 5 do cultivar BRS Valiosa e os lotes 3 e 4 do CD 208 foram submetidos ao choque térmico por $24 \mathrm{~h} \mathrm{a} 41{ }^{\circ} \mathrm{C}$ e os lotes 4 da cultivar BRS Valiosa RR 
e o 5 da CD 208 foram submetidos por 12 horas a $41{ }^{\circ} \mathrm{C}$. Os testes foram conduzidos com quatro repetições de 50 sementes para cada lote, excetuando-se o teor de água, determinado com duas repetições de 50 sementes e o teste de condutividade elétrica, realizado com oito repetições. Os procedimentos utilizados para a condução de cada teste estão descritos a seguir:

Teor de Água: determinado em estufa a $105 \pm 3{ }^{\circ} \mathrm{C}$, durante $24 \mathrm{~h}$ (Brasil, 2009). Os resultados foram expressos em percentagem (base úmida).

Germinação (substrato papel): as sementes foram distribuídas em rolos de papel toalha, umedecidos com quantidade de água equivalente a 2,5 vezes o peso do substrato seco, e colocados em câmara de germinação a $25{ }^{\circ} \mathrm{C}$ (Brasil, 2009). As avaliações foram realizadas no quinto dia, sendo os resultados expressos em percentagem de plântulas normais para cada lote e cultivar.

Germinação (substrato areia): as sementes foram distribuídas a três centímetros de profundidade, em caixas de plástico $(26 \times 16 \times 9 \mathrm{~cm})$ contendo areia peneirada, esterilizada e umedecida com água destilada até atingir $60 \%$ da capacidade de retenção. As caixas foram mantidas em laboratório, sob temperaturas entre 20 e $30^{\circ} \mathrm{C}$. A avaliação foi realizada no oitavo dia após a instalação do teste (Brasil, 2009). Os resultados foram expressos em percentagem de plântulas normais para cada lote e cultivar.

Embebição em água: inicialmente, determinouse a massa das amostras de sementes (PI) e estas foram colocadas em copos de plástico contendo $60 \mathrm{~mL}$ de água desionizada e submetidas à embebição durante seis horas, em condições de ambiente do laboratório de sementes ( 25 a $30^{\circ} \mathrm{C}$ ). Posteriormente, foram secadas mediante passagens sucessivas por bandejas de plástico com papel mataborrão no fundo, considerando-se enxutas as sementes sem brilho. Em seguida, as repetições foram pesadas para obtenção da massa final (PF) (Vieira et al., 1981 e 1982). Os resultados foram expressos em percentagem média de embebição para cada lote e cultivar.

pH do exsudato: as sementes foram embebidas em $2 \mathrm{~mL}$ de água destilada com $\mathrm{pH}=7,0$, em recipiente de plástico com células individualizadas (capacidade de $3 \mathrm{~mL}$ cada), durante 30 minutos, a $25^{\circ} \mathrm{C}$. Em seguida, adicionouse a cada célula uma gota de solução de fenolftaleína $(1 \mathrm{~g}$ dissolvido em $100 \mathrm{~mL}$ de álcool $+100 \mathrm{~mL}$ de água fervida e adição de $\mathrm{NaOH} 0,02 \mathrm{~N}$ ) e uma gota de solução de carbonato de sódio anidro ( $0,8 \mathrm{~g}$ dissolvidos em $1.000 \mathrm{~mL}$ de água destilada fervida), e agitou-se com um bastonete. A coloração resultante indica o nível de viabilidade da semente, indo do rosa forte (sementes viáveis que originarão plantas normais), passando pelo rosa fraco (sementes que originarão plântulas anormais) até o incolor (sementes mortas). Os resultados foram expressos em percentagem (Barros e Marcos Filho, 1990).

Vigor - Envelhecimento acelerado: as sementes foram distribuídas em camada única e uniforme sobre telas de inox e colocadas em caixas de germinação tampadas (11 x 11 x 3,5 cm), com $40 \mathrm{~mL}$ de água desionizada ao fundo. Estas foram mantidas em câmara de germinação a $41{ }^{\circ} \mathrm{C}$ por 48 horas (Marcos Filho, 1999a). Posteriormente, duas repetições de 50 sementes foram colocadas em estufa a $105 \pm 3{ }^{\circ} \mathrm{C}$, durante $24 \mathrm{~h}$, para determinação do teor de água e quatro repetições de 50 sementes foram submetidas ao teste de germinação (substrato papel), sendo a avaliação realizada no quinto dia após a semeadura. Os resultados foram expressos em percentagem de plântulas normais para cada lote e cultivar.

Vigor - Condutividade elétrica: sementes fisicamente puras foram pesadas e colocadas para embeber em $75 \mathrm{~mL}$ de água desionizada e mantidas em germinador a $25{ }^{\circ} \mathrm{C}$, por $24 \mathrm{~h}$. Após a embebição foi determinada a condutividade elétrica da solução e os resultados expressos em $\mu \mathrm{S} . \mathrm{cm}^{-1} \cdot \mathrm{g}^{-1}$ (Vieira, 1994).

Emergência de plântulas em campo: as sementes foram semeadas manualmente a $3 \mathrm{~cm}$ de profundidade em linhas de 2,5 m de comprimento cada, espaçadas de 50 $\mathrm{cm}$ entre si. A contagem das plântulas normais emergidas foi efetuada aos 14 dias após a semeadura (Nakagawa, 1994) e os resultados foram expressos em percentagem de plântulas normais. Os dados de temperaturas máxima e mínima, precipitação pluvial e umidade relativa do ar, referentes ao período de avaliação do teste, estão apresentados na Tabela 1 .

Análise computadorizada de imagens (SVIS ${ }^{\circledR}$ ): foram utilizadas quatro repetições de 20 sementes para cada lote. As sementes foram distribuídas em duas fileiras horizontais no terço superior de papéis toalha previamente umedecidos, posicionadas de maneira que a raiz primária pudesse crescer voltada para baixo. Em seguida, formaram-se rolos que foram mantidos em germinador a $25{ }^{\circ} \mathrm{C}$ durante três dias. Após esse período, foi realizada a aquisição das imagens das plântulas normais por meio de um scanner HP Scanjet 2004, instalado em posição invertida e operado por software Photosmart, com resolução de 100 dpi. As imagens foram analisadas pelo software Seed Vigor Imaging System $\left(\mathrm{SVIS}^{\circledR}\right)$, sendo obtidos valores médios do índice de vigor, crescimento, 
uniformidade de desenvolvimento e comprimento de plântulas para cada lote e cultivar (Hoffmaster et al., 2005; Marcos Filho et al., 2006; Marcos Filho et al., 2009).

Os dados obtidos foram analisados utilizando-se o delineamento inteiramente casualizado, com quatro e oito repetições. A comparação das médias foi realizada por intermédio do Teste de Tukey, em nível de $5 \%$ de probabilidade (Banzato e Kronka, 2006).

TABELA 1. Temperaturas máxima e mínima, precipitação pluvial e umidade relativa do ar observadas no período de 07 a 21 de outubro de 2009, em Jaboticabal, SP, durante condução do teste de emergência de plântulas em campo.

\begin{tabular}{ccccc}
\hline \multirow{2}{*}{ Dia/Mês } & \multicolumn{2}{c}{ Temperatura } & \multicolumn{1}{c}{$\begin{array}{c}\text { Precipitação } \\
\text { Pluvial }(\mathrm{mm})\end{array}$} & $\begin{array}{c}\text { Umidade } \\
\text { Relativa }(\%)\end{array}$ \\
\cline { 2 - 3 } $07 / 10$ & Máxima $\left({ }^{\circ} \mathrm{C}\right)$ & Mínima $\left({ }^{\circ} \mathrm{C}\right)$ & 0,0 & 79,2 \\
$08 / 10$ & 29,3 & 19,1 & 0,0 & 81,6 \\
$09 / 10$ & 25,3 & 16,4 & 0,0 & 70,1 \\
$10 / 10$ & 27,0 & 13,7 & 0,0 & 66,0 \\
$11 / 10$ & 30,0 & 13,7 & 0,0 & 58,1 \\
$12 / 10$ & 32,6 & 15,4 & 7,1 & 75,2 \\
$13 / 10$ & 30,5 & 18,2 & 0,0 & 74,7 \\
$14 / 10$ & 27,6 & 17,1 & 3,6 & 68,3 \\
$15 / 10$ & 32,8 & 17,4 & 1,0 & 78,7 \\
$16 / 10$ & 26,9 & 18,4 & 0,0 & 68,9 \\
$17 / 10$ & 30,5 & 16,4 & 2,2 & 70,2 \\
$18 / 10$ & 32,4 & 18,3 & 0,7 & 78,9 \\
$19 / 10$ & 30,4 & 19,0 & 7,1 & 80,7 \\
$20 / 10$ & 29,3 & 17,8 & 0,0 & 73,2 \\
$21 / 10$ & 28,5 & 16,9 & 56,7 & 69,8 \\
\hline
\end{tabular}

\section{RESULTADOS E DISCUSSÃO}

Os resultados obtidos na avaliação inicial (antes do armazenamento) do potencial fisiológico de sementes de soja dos cultivares BRS Valiosa RR e CD 208 encontramse nas Tabelas 2,3 e 4 . Os testes de $\mathrm{pH}$ do exsudato e de emergência de plântulas em campo não foram realizados nessa primeira época.

TABELA 2. Valores de teor de água inicial (TA) e após envelhecimento acelerado (TAEA), germinação em papel (TPGp) e em areia (TPGa), embebição em água (\%E), envelhecimento acelerado (EA) e condutividade elétrica (CE) de cinco lotes de semente de soja da cultivar BRS Valiosa RR.

\begin{tabular}{|c|c|c|c|c|c|c|c|}
\hline \multirow{2}{*}{ Lote } & TA & TAEA & TPGp & TPGa & $\% \mathrm{E}$ & EA & \multirow{2}{*}{$\begin{array}{c}\mathrm{CE} \\
\mu \mathrm{S} . \mathrm{cm}^{-1} \cdot \mathrm{g}^{-}\end{array}$} \\
\hline & \multicolumn{6}{|c|}{ 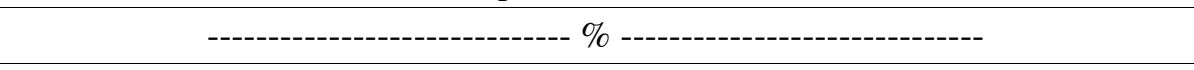 } & \\
\hline 1 & 9,0 & 26,0 & $89 \mathrm{a}$ & $95 \mathrm{a}$ & $122,6 \mathrm{a}$ & $89 \mathrm{a}$ & $71,1 \mathrm{a}$ \\
\hline 2 & 8,9 & 26,5 & $91 \mathrm{a}$ & $95 \mathrm{a}$ & $122,1 \mathrm{a}$ & $86 \mathrm{a}$ & 79,9 a \\
\hline 3 & 8,8 & 26,9 & $87 \mathrm{a}$ & $89 a b$ & $134,1 \mathrm{~b}$ & $87 \mathrm{a}$ & $85,1 \mathrm{a}$ \\
\hline 4 & 8,9 & 27,1 & $94 \mathrm{a}$ & $94 \mathrm{a}$ & $123,9 \mathrm{a}$ & $91 \mathrm{a}$ & $71,2 \mathrm{a}$ \\
\hline 5 & 9,2 & 27,7 & $90 \mathrm{a}$ & $86 \mathrm{~b}$ & $138,1 \mathrm{~b}$ & $91 \mathrm{a}$ & $84,7 \mathrm{a}$ \\
\hline $\mathrm{CV}(\%)$ & & & 4,4 & 4,2 & 1,8 & 4,6 & 15,5 \\
\hline
\end{tabular}


TABELA 3. Valores de teor de água inicial (TA) e após envelhecimento acelerado (TAEA), germinação em papel (TPGp) e em areia (TPGa), embebição em água (\%E), envelhecimento acelerado (EA) e condutividade elétrica (CE) de cinco lotes de semente de soja da cultivar CD 208.

\begin{tabular}{|c|c|c|c|c|c|c|c|}
\hline \multirow{2}{*}{ Lote } & TA & TAEA & TPGp & TPGa & $\% \mathrm{E}$ & EA & \multirow{2}{*}{$\frac{\mathrm{CE}}{\mu \mathrm{S} \cdot \mathrm{cm}^{-1} \cdot \mathrm{g}^{-1}}$} \\
\hline & \multicolumn{6}{|c|}{---------------------------- \% ---------------------------- } & \\
\hline 1 & 9,0 & 27,1 & $89 \mathrm{a}$ & 89 a & $131,4 \mathrm{a}$ & $71 \mathrm{a}$ & $100,0 \mathrm{a}$ \\
\hline 2 & 9,0 & 27,2 & $87 \mathrm{a}$ & 89 a & $128,0 \mathrm{a}$ & $69 \mathrm{a}$ & $101,0 \mathrm{a}$ \\
\hline 3 & 9,0 & 27,3 & $87 \mathrm{a}$ & $90 \mathrm{a}$ & $133,7 \mathrm{ab}$ & $78 \mathrm{a}$ & $101,4 \mathrm{a}$ \\
\hline 4 & 9,1 & 27,8 & $91 \mathrm{a}$ & $88 \mathrm{a}$ & $134,2 \mathrm{ab}$ & $77 \mathrm{a}$ & $110,0 \mathrm{a}$ \\
\hline 5 & 9,1 & 27,7 & $89 \mathrm{a}$ & $89 \mathrm{a}$ & $139,1 \mathrm{~b}$ & $78 \mathrm{a}$ & $100,4 \mathrm{a}$ \\
\hline $\mathrm{CV}(\%)$ & & & 5,7 & 4,6 & 2,4 & 7,5 & 13,8 \\
\hline
\end{tabular}

TABELA 4. Índice de vigor, crescimento, uniformidade e comprimento de plântulas ( $\mathrm{mm}$ ) de cinco lotes de sementes de soja das cultivares BRS Valiosa RR e CD 208, obtidos pela análise computadorizada de imagens $\left(\right.$ SVIS $\left.^{\circledR}\right)$.

\begin{tabular}{ccccc}
\hline \multicolumn{5}{c}{ BRS-Valiosa } \\
\hline Lote & Índice de Vigor & Crescimento $(\mathrm{mm})$ & Uniformidade $(\mathrm{mm})$ & Comprimento (mm) \\
\hline 1 & $939 \mathrm{a}$ & $945 \mathrm{a}$ & $927 \mathrm{a}$ & $97 \mathrm{a}$ \\
2 & $914 \mathrm{a}$ & $907 \mathrm{a}$ & $930 \mathrm{a}$ & $92 \mathrm{a}$ \\
3 & $959 \mathrm{a}$ & $975 \mathrm{a}$ & $925 \mathrm{a}$ & $100 \mathrm{a}$ \\
4 & $912 \mathrm{a}$ & $912 \mathrm{a}$ & $914 \mathrm{a}$ & $95 \mathrm{a}$ \\
5 & $948 \mathrm{a}$ & $961 \mathrm{a}$ & $918 \mathrm{a}$ & $68 \mathrm{a}$ \\
\hline CV $(\%)$ & 4,3 & 5,7 & 1,9 & 6,9 \\
\hline \multicolumn{2}{c}{ CD 208} & & Comprimento (mm) \\
\hline Lote & Índice de Vigor & Crescimento (mm) & Uniformidade (mm) & $75 \mathrm{a}$ \\
\hline 1 & $820 \mathrm{a}$ & $783 \mathrm{a}$ & $908 \mathrm{a}$ & $86 \mathrm{a}$ \\
3 & $780 \mathrm{a}$ & $733 \mathrm{a}$ & $890 \mathrm{a}$ & $85 \mathrm{a}$ \\
4 & $859 \mathrm{a}$ & $842 \mathrm{a}$ & $901 \mathrm{a}$ & $90 \mathrm{a}$ \\
\hline CV $(\%)$ & $854 \mathrm{a}$ & $835 \mathrm{a}$ & $901 \mathrm{a}$ & 8,6
\end{tabular}

Nota-se que os resultados dos testes de germinação em papel, de envelhecimento acelerado e de condutividade elétrica não apontaram diferenças significativas no potencial de desempenho entre os lotes dos dois cultivares, não possibilitando classificá-los em diferentes níveis. Esses resultados indicam a importância da utilização de mais de um teste para determinar o vigor de sementes, em função da variação da eficiência dos procedimentos disponíveis (Marcos Filho, 1999b).

$O$ teste de germinação em areia praticamente não acusou diferenças significativas entre os lotes do cultivar BRS Valiosa RR, sendo apenas o lote 5 considerado menos vigoroso com relação aos demais (Tabela 2). Esse resultado aproximou-se do obtido no teste de embebição em água, em que os lotes 1, 2 e 4 apresentaram-se mais vigorosos quando comparados com o 3 e o 5 . Nesse teste, lotes de melhor qualidade são aqueles que apresentam menor porcentagem de embebição de água pela semente e os de pior qualidade, maior embebição.

Para a cultivar CD 208 (Tabela 3), apenas o teste rápido de embebição em água detectou diferenças de potencial fisiológico, sendo os lotes 1 e 2 superiores aos demais. As diferenças na embebição podem ser atribuídas à menor resistência oferecida pelo tegumento, dado o 
aumento da permeabilidade com a elevação do grau de deterioração da semente (Vieira et al., 1982).

$\mathrm{Na}$ avaliação do vigor das sementes, mediante a análise computadorizada de imagens de plântulas (SVIS ${ }^{\circledR}$ ) (Figura 1), os resultados obtidos para as duas cultivares não permitiram a diferenciação dos lotes (Tabela 4).
Esses resultados podem ser explicados pela estreita diferença entre o potencial fisiológico das sementes, uma vez que análises SVIS ${ }^{\circledR}$ mostraram-se sensíveis na determinação do vigor de sementes de soja com maiores variações entre lotes (Sekharan, 2005; Marcos Filho et al., 2009).
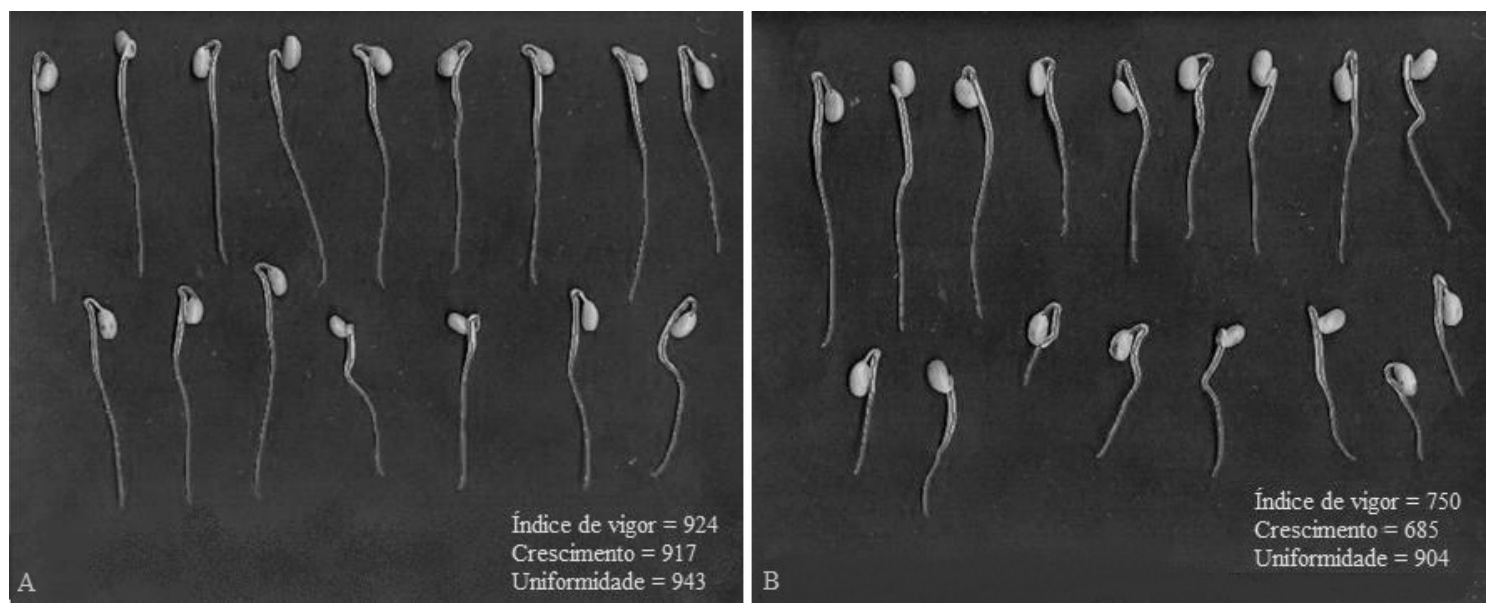

FIGURA 1. Imagens digitais de plântulas de soja das cultivares BRS Valiosa RR (A) e CD 208 (B) analisadas pelo sistema automatizado de avaliação do vigor de sementes (SVIS ${ }^{\circledR}$ ).

Com relação ao potencial fisiológico das sementes após armazenamento e choque térmico (Tabelas 5 e 6), apenas os resultados dos testes de embebição em água e de condutividade elétrica indicaram variação significativa entre lotes para ambas as cultivares, sendo que essa variação foi similar entre os testes, em especial para o cultivar BRS Valiosa RR. Tais resultados podem ser justificados pelo princípio dos testes, visto que ambos baseiam-se na relação entre a integridade das membranas celulares e o processo de deterioração; contudo, o teste de embebição demonstra apenas o caráter físico do processo, concentrando-se na capacidade de organização das membranas, ao passo que o teste de condutividade elétrica fundamenta-se também na perda de íons, açúcares e metabólitos em vista da alteração da integridade das membranas (Fessel et al., 2010).

TABELA 5. Valores de teor de água inicial (TA) e após envelhecimento acelerado (TAEA), germinação em papel (TPGp) e em areia (TPGa), embebição em água (\%E), pH do exsudato (pH), envelhecimento acelerado (EA), emergência de plântulas em campo (EC) e condutividade elétrica (CE) de cinco lotes de semente de soja da cultivar BRS Valiosa RR após três meses de armazenamento e choque térmico.

\begin{tabular}{|c|c|c|c|c|c|c|c|c|c|}
\hline \multirow{2}{*}{ Lote } & TA & TAEA & TPGp & TPGa & $\mathrm{E} \%$ & $\mathrm{pH}$ & EA & $\mathrm{EC}$ & \multirow{2}{*}{$\begin{array}{c}\mathrm{CE} \\
\mu \mathrm{S} \cdot \mathrm{cm}^{-1} \cdot \mathrm{g}^{-1}\end{array}$} \\
\hline & \multicolumn{8}{|c|}{---------------------------------------------- $\%$------------------------------------------- } & \\
\hline 1 & 10,1 & 27,1 & $91 \mathrm{a}$ & $87 \mathrm{a}$ & $131,1 \mathrm{a}$ & $89 \mathrm{a}$ & $93 \mathrm{a}$ & $87 \mathrm{a}$ & $72,9 \mathrm{a}$ \\
\hline 2 & 10,2 & 26,4 & $88 \mathrm{a}$ & $90 \mathrm{a}$ & 131,9 a & $90 \mathrm{a}$ & $88 \mathrm{a}$ & $90 \mathrm{a}$ & $79,2 \mathrm{abc}$ \\
\hline $3^{1}$ & 10,1 & 28,3 & $91 \mathrm{a}$ & $81 \mathrm{a}$ & $145,5 \mathrm{~b}$ & $93 \mathrm{a}$ & $86 \mathrm{a}$ & $93 \mathrm{a}$ & $88,8 \mathrm{c}$ \\
\hline $4^{2}$ & 10,0 & 27,0 & $88 \mathrm{a}$ & $90 \mathrm{a}$ & $132,0 \mathrm{a}$ & $91 \mathrm{a}$ & $89 \mathrm{a}$ & $93 \mathrm{a}$ & $77,2 \mathrm{ab}$ \\
\hline $5^{1}$ & 10,1 & 27,9 & $89 a$ & $87 \mathrm{a}$ & $144,8 \mathrm{~b}$ & $90 \mathrm{a}$ & $89 a$ & $93 a$ & 86,2 bc \\
\hline $\mathrm{CV}(\%)$ & & & 6,4 & 4,8 & 1,3 & 3,2 & 8,2 & 9,4 & 8,4 \\
\hline
\end{tabular}

${ }^{1}$ Choque térmico à $41{ }^{\circ} \mathrm{C}$ por $24 \mathrm{~h} . \quad{ }^{2}$ Choque térmico à $41{ }^{\circ} \mathrm{C}$ por $12 \mathrm{~h}$ 
TABELA 6. Valores de teor de água inicial (TA) e após envelhecimento acelerado (TAEA), germinação em papel (TPGp) e em areia (TPGa), embebição em água (\%E), pH do exsudato (pH), envelhecimento acelerado (EA), emergência de plântulas em campo (EC) e condutividade elétrica (CE) de cinco lotes de semente de soja da cultivar CD 208 após três meses de armazenamento e choque térmico.

\begin{tabular}{|c|c|c|c|c|c|c|c|c|c|}
\hline \multirow{2}{*}{ Lote } & TA & TAEA & TPGp & TPGa & $\mathrm{E} \%$ & $\mathrm{pH}$ & EA & EC & \multirow{2}{*}{$\begin{array}{c}\mathrm{CE} \\
\mu \mathrm{S} . \mathrm{cm}^{-1} \cdot \mathrm{g}^{-1}\end{array}$} \\
\hline & \multicolumn{8}{|c|}{--------------------------------------------- $\%$------------------------------------------- } & \\
\hline 1 & 10,3 & 29,3 & $81 \mathrm{a}$ & $88 \mathrm{a}$ & $139,9 \mathrm{~b}$ & $93 \mathrm{a}$ & $75 \mathrm{a}$ & $89 \mathrm{a}$ & $101,8 \mathrm{a}$ \\
\hline 2 & 10,3 & 26,3 & $73 \mathrm{a}$ & $84 \mathrm{a}$ & $129,7 \mathrm{a}$ & $84 \mathrm{a}$ & $68 \mathrm{a}$ & $85 \mathrm{a}$ & $108,3 \mathrm{ab}$ \\
\hline $3^{1}$ & 10,2 & 28,2 & $73 \mathrm{a}$ & $81 \mathrm{a}$ & $141,4 \mathrm{~b}$ & $93 \mathrm{a}$ & $64 \mathrm{a}$ & $88 \mathrm{a}$ & $120,7 \mathrm{~b}$ \\
\hline $4^{1}$ & 10,2 & 27,9 & $82 \mathrm{a}$ & $86 \mathrm{a}$ & $140,3 \mathrm{~b}$ & $87 \mathrm{a}$ & $75 \mathrm{a}$ & $81 \mathrm{a}$ & $99,4 \mathrm{a}$ \\
\hline $5^{2}$ & 10,1 & 27,9 & $81 \mathrm{a}$ & $85 \mathrm{a}$ & $141,8 \mathrm{~b}$ & $89 a$ & $77 \mathrm{a}$ & $87 \mathrm{a}$ & $102,3 \mathrm{a}$ \\
\hline $\mathrm{CV}(\%)$ & & & 13,2 & 5,5 & 1,3 & 5,7 & 13,6 & 9,2 & 10,7 \\
\hline
\end{tabular}

${ }^{1}$ Choque térmico a $41^{\circ} \mathrm{C}$ por $24 \mathrm{~h} . \quad{ }^{2}$ Choque térmico a $41^{\circ} \mathrm{C}$ por $12 \mathrm{~h}$

A classificação dos lotes no teste de embebição manteve-se após o choque térmico para a cultivar BRSValiosa, havendo apenas aumento no grau de deterioração das sementes, já que a taxa de embebição das amostras após o armazenamento foi superior à verificada na época anterior. O lote 2 da cultivar CD 208 apresentou maior vigor, enquanto o restante dos lotes foi caracterizado como de menor vigor. Neste caso, os lotes que possuíam vigor médio na primeira avaliação apresentaram redução do vigor, podendo esse efeito ser consequência do choque térmico ou do próprio armazenamento, uma vez que o lote 1 não passou pelo choque térmico e mostrou queda significativa do vigor.

No que diz respeito ao teste de condutividade elétrica, o lote 1 da cultivar BRS Valiosa RR foi mais vigoroso e o lote 3 , menos vigoroso. Os lotes 1,4 e 5 da cultivar CD 208 apresentaram maior vigor e, apesar de não ter havido diferença significativa entre os lotes nos testes de envelhecimento acelerado e de germinação em papel, esses lotes apresentaram maior porcentagem de plântulas normais nesses testes, coincidindo com os resultados encontrados no teste de condutividade elétrica.

As diferenças entre lotes encontradas na segunda época deveram-se ao armazenamento de sementes, pois nesse período ocorrem mudanças degenerativas que levam, eventualmente, à perda de viabilidade, não germinando mais sob aquelas condições consideradas favoráveis para a germinação (Lin, 1988).

$\mathrm{O}$ teste de $\mathrm{pH}$ do exsudato não foi eficiente na separação dos lotes de sementes, diferentemente do observado por Santana et al. (1998) para milho e por Amaral e Peske (1984) para soja. As médias obtidas nos testes de envelhecimento acelerado e de emergência de plântulas em campo não possibilitaram a separação dos lotes em diferentes níveis de vigor, como verificado por Vanzolini et al. (2007) em trabalho com sementes de soja da cultivar EMBRAPA 48. Possivelmente este resultado esteja associado ao fato de que, durante a execução do teste de emergência de plântulas em campo, as condições do ambiente foram adequadas e as sementes possuíam elevado poder germinativo e vigor, o que pode ter favorecido a uniformidade dos dados.

Pode-se verificar que, de modo geral, os testes de embebição em água, envelhecimento acelerado e condutividade elétrica após armazenamento detectaram a redução no vigor dos lotes, indicando que o período de armazenamento, mesmo sendo 90 dias, foi suficiente para que progredisse o processo de deterioração. As condições de armazenamento utilizadas nesse trabalho foram favoráveis à preservação das sementes; entretanto, lotes com diferentes níveis de vigor podem ter comportamentos diferenciados quanto à deterioração (Carvalho e Von Pinho, 1997; Pádua e Vieira, 2001; Forti et al., 2010).

Apesar de ser pouco utilizado na avaliação rotineira da qualidade de sementes, o teste de embebição em água permitiu a separação dos lotes de maneira clara em diferentes níveis de vigor e, por ser um teste relativamente rápido em sua execução, possibilita tomadas de decisão antecipadas durante as etapas do processo produtivo, diminuindo riscos e prejuízos que podem ser ocasionados pela utilização de sementes de baixo potencial germinativo. Por esse motivo, merece atenção na condução de pesquisas sobre a avaliação do potencial fisiológico.

Deve-se salientar também que o fato de não se 
ter havido diferenciação clara em níveis de vigor considerando procedimentos já tradicionais, como envelhecimento acelerado e condutividade elétrica, isso não significa que esses procedimentos sejam ineficientes. A consideração principal leva ao fato do trabalho ter sido realizado com lotes de sementes com alto potencial fisiológico, de modo que tais procedimentos não foram suficientes para identificar variações no comportamento desses lotes. Sabe-se que o primeiro evento do processo de deterioração é a desestabilização do sistema de membranas celulares, de modo que testes que avaliam essa situação podem ser considerados mais sensíveis a diferenças de vigor entre lotes de sementes.

\section{CONCLUSÃO}

O teste de embebição em água para a avaliação rápida da viabilidade de semente possibilita a classificação de lotes de sementes de soja quanto ao potencial fisiológico, antes e após o armazenamento, constituindo alternativa promissora para a composição de programas de controle de qualidade.

\section{REFERÊNCIAS}

AMARAL, A.S.; PESKE, S.T. pH como parâmetro para estimar a germinação de sementes de soja. Passo Fundo, APASSUL, 1984. 4p.

AMARAL, A.S.; PESKE, S.T. Testes para avaliação rápida da qualidade fisiológica de sementes de trigo. Revista Brasileira de Agrociência, v.6 n.1, p.12-15, 2000. http:// www.ufpel.tche.br/faem/agrociencia/v6n1/artigo02.pdf

BANZATO, D.A.; KRONKA, S.N. Experimentação agrícola. 4.ed. Jaboticabal: FUNEP, 2006. 237p.

BARROS, A.S.R.; MARCOS FILHO, J. Testes para avaliação rápida da viabilidade de sementes de soja. Pesquisa Agropecuária Brasileira, v.25, n.10, p.14471459, 1990.

BARROS, A.S.R.; MARCOS FILHO, J. Testes para avaliação rápida do vigor de sementes de soja. Revista Brasileira de Sementes, v.19, n.2, p.288-294, 1997. http:// www.abrates.org.br/revista/artigos/1997/v19n2/artigo24. pdf

BRASIL. Ministério da Agricultura, Pecuária e Abastecimento. Regras para análise de sementes. Ministério da Agricultura, Pecuária e Abastecimento. Secretaria de Defesa Agropecuária. Brasília, DF: Mapa/
ACS, 2009. 395p. http://www.bs.cca.ufsc.br/publicacoes/ regras $\% 20$ analise $\% 20$ sementes.pdf

CABRERA, A.C.; PESKE, S.T. Testes do pH do exsudato para sementes de milho. Revista Brasileira de Sementes, v.24, n.1, p.134-140, 2002. http://www.abrates.org.br/ revista/artigos/2002/v24n1/artigo19.pdf

CARVALHO, M.L.M.; PINHO, E.V.R. Armazenamento de sementes. Lavras: UFLA/FAEPE, 1997. 67p.

CARVALHO, L.F.; SEDIYAMA, C.S.; REIS, M.S.; DIAS, D.C.F.S.; MOREIRA, M.A. Influência da temperatura de embebição da semente de soja no teste de condutividade elétrica para avaliação da qualidade fisiológica. Revista Brasileira de Sementes, v.31, n.1, p.9-17, 2009. http:// www.scielo.br/pdf/rbs/v31n1/a01v31n1.pdf

DELL'AQUILA, A. Development of novel techniques in conditioning, testing and sorting seed physiological quality. Seed Science and Technology, v.37, n.3, p.608-624, 2009. http://docserver.ingentaconnect.com/deliver/connect/ ista/02510952/v37n3/s10.pdf?expires $=1289327053 \& \mathrm{id}=5$ $9615216 \&$ titleid $=75001181 \&$ accname $=$ Universidade + Est adual+Paulista+(UNESP)+'Julio+de+Mesquita+Filho'\&c hecksum=083D410287850CD6F7D73D5D3C69270E

FESSEL, S.A.; PANOBIANCO, M.; SOUZA, C.R.; VIEIRA, R.D. Teste de condutividade elétrica em sementes de soja armazenadas sob diferentes temperaturas. Bragantia, v.69, n.1, p.207-214, 2010. http://www.scielo. br/pdf/brag/v69n1/26.pdf

FORTI, V.A.; CICERO, S.M.; PINTO, T.L.F. Avaliação da evolução de danos por "umidade" e redução do vigor em sementes de soja, cultivar TMG113-RR, durante o armazenamento, utilizando imagens de raios $\mathrm{x}$ e testes de potencial fisiológico. Revista Brasileira de Sementes, v.32, n.3, p.123-133. 2010. http://www.scielo.br/pdf/rbs/ v32n3/v32n3a14.pdf

HOFFMASTER, A.F.; XU, L.; FUJIMURA, K.; MCDONALD, M.B.; BENNETT, M.A.; EVANS, A.F. The Ohio State University seed vigor imaging system (SVIS) for soybean and corn seedlings. Seed Technology, v.27, n.1, p.7-24, 2005.

LIN, S.S. Efeito do período de armazenamento na lixiviação eletrolítica dos solutos celulares e qualidade fisiológica da semente de milho (Zea mays L.) e feijão (Phaseolus vulgaris L.). Revista Brasileira de Sementes, v.10, n.3, p.59-67, 1988. http://www.abrates.org.br/revista/ artigos/1988/v10n3/artigo05.pdf

MARCOS FILHO, J. Teste de envelhecimento acelerado. In: KRZYZANOWSKI, F.C.; VIEIRA, R.D.; FRANÇA 
NETO, J.B. (Ed.) Vigor de sementes: conceitos e testes. Londrina: ABRATES. 1999a. cap.3, p.1-24.

MARCOS FILHO, J. Testes de vigor: importância e utilização. In: KRZYZANOWSKI, F.C.; VIEIRA, R.D.; FRANÇA NETO, J.B. (Ed.) Vigor de sementes: conceitos e testes. Londrina: ABRATES. 1999b. cap. 1, p.1-21.

MARCOS FILHO, J.; BENNETT, M.A.; McDONALD, M.B.; EVANS, A.F.; GRASSBAUGH, E.M. Assessment of melon seed vigour by na automated computer imaging system compared to traditional procedures. Seed Science and Technology, v.34, n.2, p.485-497, 2006. http://docserver.ingentaconnect.com/deliver/connect/ ista/02510952/v34n2/s23.pdf?expires $=1289327826 \& \mathrm{id}=5$ 9615473\&titleid $=75001181 \&$ accname $=$ Universidade + Est adual+Paulista+(UNESP)+'Julio+de+Mesquita+Filho' \&c hecksum $=6 \mathrm{E} 738 \mathrm{~F} 27150 \mathrm{DE} 15091 \mathrm{C} 1671246 \mathrm{~F} 180 \mathrm{D} 7$

MARCOS FILHO, J.; KIKUTI, A.L.P.; LIMA, L.B. Métodos para avaliação do vigor de sementes de soja, incluindo a análise computadorizada de imagens. Revista Brasileira de Sementes, v.31, n.1, p.102-112, 2009. http:// www.scielo.br/pdf/rbs/v31n1/a12v31n1.pdf

NAKAGAWA, J. Testes de vigor baseados na avaliação das plântulas. In: VIEIRA, R. D.; CARVALHO, N.M. (Ed.) Testes de vigor em sementes. Jaboticabal: FUNEP, 1994. p.48-85.

PÁDUA, G.P.; VIEIRA, R.D. Deterioração de sementes de algodão durante o armazenamento. Revista Brasileira de Sementes, v.23, n.2, p.255-262, 2001. http://www.abrates. org.br/revista/artigos/2001/v23n2/artigo35.pdf

ROCHA, V.S.; SEDIYAMA, T.; DA SILVA, R.F. da; SEDIYAMA, C.S.; THIÊBAUT, J.T.L. Embebição de água e potencial fisiológico de sementes de soja. Revista Brasileira de Sementes, v. 6, n.2, p.51-66, 1984. http:// www.abrates.org.br/revista/artigos/1984/v6n2/artigo06. $\underline{\mathrm{pdf}}$

SAKO, Y.; MCDONALD, M.B.; FUJIMURA, K.; EVANS, A.F.; BENNETT, M.A. A system for automated seed vigour assessment. Seed Science and Technology, v.29, n.3, p.625-636, 2001.

SANTANA, D.C.; GRAÇAS, M.D.; VIEIRA, G.C.; CARVALHO, M.L.M.; OLIVEIRA, M.C. Teste do pH do exsudato-fenolftaleína para rápida definição sobre o destino de lotes de sementes de milho. Revista Brasileira de Sementes, v.20, n.1, p.160-166, 1998. http://www. abrates.org.br/revista/artigos/1998/v20n1/artigo27.pdf

SCHUCH, L.O.B.; KOLCHINSKI, E.M.; FINATTO, J.A. Qualidade fisiológica da semente e desempenho de plantas isoladas em soja. Revista Brasileira de Sementes, v.31, n.1, p.144-149, 2009. http://www.scielo.br/pdf/rbs/v31n1/ a16v31n1.pdf

SEKHARAN, S. Aged soybean seeds - their physiology and vigor assessment. 2006. 180f. Tese (Ph.D) - The Ohio State University, Columbus/OH/EUA, 2005.

SILVA, M.A.D.; VIEIRA, R.D.; SANTOS, J.M. Influência do envelhecimento acelerado na anatomia da testa de sementes de soja, cv. Monsoy 8400. Revista Brasileira de Sementes, v.30, n.2, p.91-99, 2008. http://www.scielo.br/ $\mathrm{pdf} / \mathrm{rbs} / \mathrm{v} 30 \mathrm{n} 2 / \mathrm{a} 12 \mathrm{v} 30 \mathrm{n} 2 . \mathrm{pdf}$

VANZOLINI, S.; ARAKI, C.A.S.; SILVA, A.C.T.M.; NAKAGAWA, J. Teste de comprimento de plântula na avaliação da qualidade fisiológica de sementes de soja. Revista Brasileira de Sementes, v.29, n.2, p.90-96, 2007. http://www.scielo.br/pdf/rbs/v29n2/v29n2a12.pdf

VIEIRA, R.D. Teste de condutividade elétrica. In: VIEIRA, R.D.; CARVALHO, N.M. (Ed.). Testes de vigor em sementes. Jaboticabal: FUNEP, 1994. p.103-132.

VIEIRA, R.D.; SEDIYAMA，T.; SILVA， R.F. da; SEDIYAMA, C.S.; THIEBAUT, J.T.L. Avaliação do potencial fisiológico de sementes de quatorze cultivares de soja (Glycine $\max$ (L.) Merrill). Revista Ceres, v.30, n.172, p.408-418, 1983.

VIEIRA, R.D.; SEDIYAMA, T.; SILVA, R.F. da; SEDIYAMA, C.S.; THIEBAUT, J.T.L. Efeito do retardamento da colheita, sobre a qualidade de sementes de soja cv 'UFV-2'. Revista Brasileira de Sementes, v.4, n.2, p.9-22, 1982. http://www.abrates.org.br/revista/ artigos/1982/v4n2/artigo01.pdf

VIEIRA， R.D.; SEDIYAMA， T.; SILVA， R.F. da; SEDIYAMA, C.S.; THIEBAUT, J.T.L.; XIMENES, P.A. Estudo da potencial fisiológico de sementes de soja (Glycine $\max ($ L.) Merrill), cultivar UFV-1, em quinze épocas de colheita. In: SEMINÁRIO NACIONAL DE PESQUISA DE SOJA, 2, 1981, Brasília. Anais... Londrina: EmbrapaCNPSo, 1981. p.633-644. 